Running Head: Self-Assembly

\title{
Self-Assembly, Self-Organization: Nanotechnology and Vitalism ${ }^{1}$
}

Bernadette Bensaude-Vincent

Professeur d'histoire et de philosophie des sciences

Université Paris X

200 Avenue de la république

92001 NANTERRE

FRANCE

Tel/Fax: 33147323183

bensaude@u-paris10.fr

Abstract:

Over the past decades, self-assembly has attracted a lot of research attention and transformed the relations between chemistry, materials science and biology. The paper explores the impact of the current interest in self-assembly techniques on the traditional debate over the nature of life. The first section describes three different research programs of self-assembly in nanotechnology in order to characterize their metaphysical implications: -1 - Hybridization ( using the building blocks of living systems for making devices and machines) ; -2Biomimetics (making artifacts mimicking nature); -3- Integration (a composite of the two previous strategies). The second section focused on the elusive boundary between selfassembly and self-organization tries to map out the various positions adopted by the promoters of self-assembly on the issue of vitalism?

Keywords: biomimetics, hybridization, bionanotechnology, nature and artifact, chemistry, biology, cybernetics.

\footnotetext{
${ }^{1}$ An earlier and longer version of this paper has been presented as position paper at the France/Stanford Meeting organized by Jean-Pierre Dupuy in Avignon, December 2006. I am grateful for the comments of participants.
} 


\section{Self-Assembly, Self-Organization: Nanotechnology and Vitalism}

Put the different parts of a car in a big box, and shake the whole, will you get a car? This image is often used to express what self-assembly can achieve. ${ }^{1}$ Spontaneous arrangements of small building blocks in ordered patterns or structures are ubiquitous in living systems, and they are crucial for designing at the nanoscale, where human hands and tools are helpless. Self-assembly is extremely advantageous from a technological point of view because it is a spontaneous and reversible process with little or no waste and a wide domain of applications ranging from nucleation of inorganic particles, formation of vesicles, monolayers, supramolecules, etc.

Over the past decades, self-assembly has attracted a lot of research attention and transformed the relations between chemistry, materials science and biology. A bibliometric survey of the occurrences of the term "self-assembly" in comprehensive data-bases (the ISI: Science Citation Index/SCI and Social Science Citation Index/SSCI) by Sabine Maasden and Mario Kaiser reveals a spectacular increase over the past twenty years. ${ }^{2}$ According to their survey about $10 \%$ of the papers devoted to nanotechnology address the concept of self-assembly. Among them a small portion (about 3\%) are dealing with self-organization (176 over an amount of 5741 papers in the year 2005).

\begin{tabular}{|cccc}
\multicolumn{4}{|c}{ Table 1: Self-Assembly occurrences in SCI \& SSCI } \\
\hline 1990 & 1995 & 2000 & 2005 \\
$\mathbf{8 6}$ & $\mathbf{8 0 7}$ & $\mathbf{2 4 4 4}$ & $\mathbf{5 7 4 1}$ \\
\hline
\end{tabular}

A wide spectrum of self-assembly techniques have been developed and described in the technical literature. ${ }^{3}$ The car metaphor is rather used in semi-popular publications. It is meant to emphasize the novelty of nanotechnology and the radical break with conventional top down fabrication techniques. On the other hand, it conveys a kind of magic power to nanoscientists. ${ }^{4}$ The access to the nanoscale also triggers the ambition to create artificial cells and to unveil the mystery of the origin of life.

From a historical perspective, self-assembly strikes as a new episode in a long tradition of Faustian ambitions to rival with life. Paracelsus already claimed that alchemists could create an artificial human being, a homonculus in a test-tube. ${ }^{5}$ Later on nineteenth-century chemists

\footnotetext{
${ }^{1}$ Drexler, (1986) p. 2 ; Richard Jones rather used the metaphor of the jigsaw puzzle (Jones, 2004, p. 91-93)

${ }^{2}$ Maasden (2006)

${ }^{3}$ see Whitesides and Boncheva (2002), Zhang Shuguang (2003), MRS Bulletin, 31 January 2006,

${ }^{4}$ Actually some scientists like to play magics. In a European conference of chemistry (Budapest, August 2006), David Leigh from Edinburgh performed magic tricks while presenting the results of his work on self-assembly.

${ }^{5}$ See William R. Newman (2004)
} 
spread the legend that the synthesis of urea by Friedrich Wöhler destroyed the metaphysical belief in the existence of a vital force since chemistry was able to synthesize substances so far made only by living organisms. ${ }^{6}$ It was not difficult however for physiologists such as Claude Bernard to ridicule their claims by pointing to the huge difference between their laboratory processes and nature's processes. Chemists could certainly synthesize the products of life but could not imitate the ways of nature in their vessels and furnaces. ${ }^{7}$ Thus their antimetaphysical claim proceeded from two confusions: between "organic" and "organized" and between product and process. However today chemists seem to be in a better position to silence Bernard's objection. Self-assembly seems to open a path for emulating nature's processes. Are we going to witness a new episode of the endless fight between vitalism and reductionism? Will history repeat itself? And to plagiarize Marx's famous remark, while putting it upside down: shall we say that the first time it was a comedy and that the second time it could be a tragedy?

\section{Three distinctive research programs}

The purpose of this section is not to survey the various strategies of self-assembly at the interface between nanotechnology and biology, which are described in today's scientific literature. ${ }^{8}$ Rather I try to distinguish various research programs using self-assembly, to make a kind of typology. I do not claim that this tentative categorization does justice to the entire field. As I take for granted the antipositivistic claim that there is no science without implicit metaphysics, I will try to identify the metaphysical assumptions underlying the three categories here distinguished.

- 1 - Using the building blocks of living systems for making devices and machines is the strategy that can be named hybridization.

-2- Biomimetics is making artifacts mimicking nature

- 3-Integration is a kind of composite of the two previous strategies. However like most composite materials this one is more than the sum of its ingredients as it rests on quite different metaphysical views.

The three research programs here described rely on the assumption that artifacts and natural systems share some features and often use the machine metaphor to describe living systems. But the metaphor works in two different ways. Either technological vocabulary is applied to living organisms and describes them as machines or organic metaphors are used to describe our devices and machines. In the 1970s, the French philosopher Georges Canguilhem noticed that the analogy between organism and machines always works one way: organisms being described in technological terms. ${ }^{9}$ But nowadays it is more and more usual to describe machines in biological terms. The distance between machines and organisms tends to be blurred.

\section{Hybridization}

An obvious way to self-assemble the parts of our machines is to take advantage of the exquisite structures and devices selected by biological evolution. For instance, using biology to build nanoelectronic circuits that assemble without human manipulation. When Erez Braun,

\footnotetext{
${ }^{6}$ Marcelin Berthelot (1897) p. 265-77. On the urea synthesis legend see Brooke, J.H., 1973), Ramberg P., 2000.

${ }^{7}$ Bernard Claude [1878] p. 202-229.

${ }^{8}$ See for instance Ball (2002)

${ }^{9}$ Canguilhem [1947].
} 
a biophysicist from Technion at Haïfa announced that he used the complementarity of DNA strands for making nanotransistors, the news was widely reported. ${ }^{10}$ Now it is current routine practice in the laboratory waiting for applications at industrial scale.

The designer of such machines borrow a specific material or device "invented" by biological evolution regardless of its specific environment. Indeed traditional technologies have been doing that for centuries. They used to extract resources such as wood, bone, or skin and process them to make a variety of artifacts. Similarly nanotechnology extracts a number of small units as close as possible to the building blocks of living systems (DNA, bacteria,..) in order to build artifacts from bottom-up.

This strategy requires that the living cell be viewed as a collection of machines operating together. "Molecular machine" is a fashionable expression. It is currently used both by molecular biologists who describe DNA, RNA, enzymes, proteins as nanomachines and by materials chemists who are building molecular motors or rotors. Living systems are viewed as molecular manufactures and the analogy is often used as a proof that we can make it. But there is little chance that we can emulate nature, which spent billions of years for designing and perfecting high-performance structures capable of sustaining life. It seems more reasonable to start from the building blocks provided by nature - whether they be proteins, bacteria, micelles or colloids - in order to achieve our own goals. Steven Boxer, a chemist from Stanford who uses proteins as transistors in electronic circuits, thus describes his strategy: "We've decided that since we can't beat them (biomolecular systems), we should join them". "Joining" may not be the most appropriate term for two reasons: i) biomolecular systems have to be decomposed in a number of elementary units, redefined as functionalities, and abstracted from their own environment; ii) they have to be processed and modified through genetic engineering to perform specific tasks in an artificial environment. To consider such uses as a form of partnership ("join") you have to consider that biological systems are fully and adequately described in terms of a collection of independent devices that can be abstracted from their environment and re-used in other environments.

In my view this strategy is more adequately depicted as appropriation of biological items in the dual sense of the term (at least in French): i) they are processed through various techniques (recombination, gene modification, ...) in order to be adjusted and adapted to human purposes; ii) they become our intellectual property and can consequently be patented.

Further analysis of the model of machines underlying this strategy points to a number of characteristic features. In fact, the analogy between nature and artifacts is self-reinforcing. The more machines try to resemble living organisms, the more nature is artificialized. However, as shown from the chart below, molecular biologists do not care for shaping a consistent metaphor. Rather they pick up images from a variety of technologies - mechanical engineering, electrical circuitry, information technology... A living cell looks more like a warehouse or a garage, than like a modern manufacture.

Table 2 What do they have in common? Machines and molecular machines (From Zhang , 2003, p. 1174)

$\begin{array}{cc}\text { Machines } & \text { Molecular machines } \\ \text { Vehicles } & \text { Hemoglobin } \\ \text { Assembly lines } & \text { Ribosomes } \\ \text { Motors, generators } & \text { ATP synthases } \\ \text { Train tracks } & \text { Actin filament network }\end{array}$

\footnotetext{
${ }^{10}$ Keren K, Berman R S., Buchstab E., Sivan U., and Braun E. (2003)

${ }^{11}$ Steven Boxer (1991)
} 
Train controlling center

Digital databases

Copy machines

Chain couplers

Bulldozer, destroyer

Mail sorting machines

Electric fences

Gates, keys, passes

Internet nodes
Centrosome

Nucleosomes

Polymerases

Ligases

Proteases, proteosomes

Protein sorting mechanisms

Membranes

Ion channels

Neuron synapses

More importantly the cell seems to be a collection of independent parts, each of them designed for performing a specific task. In this respect the cell machinery is a very classical machine, such as clocks. In classical or "Cartesian" machines, each individual component is assigned a definite function. ${ }^{12}$ Each functional part is independent from the others and has to be assembled together by a specific tool. For instance, Drexler's universal assemblers, modelled on ribosomes, pick and place atoms to assemble them. In this model of machine where each task is correlated with one component, self-assembly becomes a self-contradictory notion. For the machine to be ideal, assembly has to be a functionality belonging to an individual unit rather than a property of the whole. All spontaneous tendency to self-assemble, to stick together is an obstacle.

\section{Biomimetics}

An alternative strategy is to mimic nature. Even before the nano-tsunami, self-assembly has prompted collaborations between materials scientists and biologists. ${ }^{13}$ Materials scientists who turned their attention to natural composites such as wood, bone, muscles, or natural fibers such as spider silk were fascinated by nature's multifunctional structures and efficient processes. For Mekmet Sarikaya et Olhan Aksai “ biomimetics is the study of biological structures, their function, and their synthetic pathways, in order to stimulate and develop these ideas into synthetic systems similar to those found in biological systems.

The phrase "synthetic systems" suggests that the machine metaphor no longer guides the interpretation of self-assembly and that a more systemic approach prevails.

In fact, biomimicry cannot be just copying a model. Mimicking biology never meant duplicating the original in all its details or faking it, as could be the case with fine arts copies. Even when materials scientists mimic marine shells for making strong composites, or lotus leaves for making non-wetting glass, they do not make indistinguishable copies. They usually select essential aspects of biomaterials. Yet generally their model is less a living system than a local pattern or device whose performances are interesting for engineers.

When it comes to mimicking processes such as self-assembly, then the laboratory cannot exactly copy the model. Chemists usually operate at high temperatures, in high vacuum and with organic solvents, while nature is able to operate at room temperature, in rather messy and aqueous environments as well as in very extreme conditions. Nature provides inspiration rather than models.

Whereas designers trying to replicate a model have to acquire an in depth knowledge of its fine-grained structure and to look at details through the eyes of botanists, by contrast for

\footnotetext{
${ }^{12}$ Bensaude-Vincent, Guchet (2007)

${ }^{13}$ Sarikaya \& Aksay (1995), Bensaude-Vincent, Arribart \& al. (2002)

${ }^{14}$ Sarikaya et Aksay eds, (1995) p.xi
} 
drawing lessons from nature, materials scientists have to abstract the basic principles and the major constraints at work in living organisms before designing their own behavior and strategy. The promises of self-assembly for nanotechnology have thus prompted a number of research programs in molecular biology and biophysics aimed at understanding the process of self-assembly such as protein-folding or the use of templates generating geometrical constraints.

As a result it is clearly established that self-assembly requires at least two conditions: i) reversibility is crucial for allowing the recombination of parts. Self-assembly relies on noncovalent bonds such as hydrogen -bonding, electrostatic or ionic bonds and labile interactions. ii) the information must be contained in the reagents, encoded in the components rather than provided by an external program.

Ironically the study of the basic principles of self-assembly led to conclusions emphasizing the distance between organisms and machines. This is a major result of nanobiotechnology that goes usually unnoticed. In biomimetic strategies, the convergence between nano and bio does not rest on similarities. Rather it requires the clear recognition of the differences between biological environment and technological environment. A number of contrasts are listed in the tentative chart below which should be refined and probably extended.

\section{Table 3 Contrasts between natural and artificial designs}

\section{Living Systems}

Ambient Temperature +

Low energy (ATP)

Mobility of the components

Brownian motion

Order out of noise

Plasticity: conformation changes in response

to environment

Adhesive Surfaces (van deer Waals)

Variable number of components

Instructions for assembly inherent in the components

Local equilibrium between forces

Correction through trials and errors

Robustness through stochasticity

\section{Human technology}

High temperatures (difference needed)

High energy

No or few fluctuations

Noise as nuisance

Rigid components

Separated Surfaces

Fixed number of components

Instructions for assembly from outside

Central Control

Robustness through redundancy

Emphasizing the contrasts between conventional engineering and biological processes was typically Richard Jones's enterprise in Soft machines. ${ }^{15}$ Jones insists that biological machines work with Brownian motion and that "a different feature of the physics that leads to problems for one type of design may be turned to advantage in a design that is properly optimised for this different world". ${ }^{16}$ The properties characteristic of the nanoscale, which are problems for conventional machines, will have to be used as positive opportunities by nanoengineers. Jones thus contrasted two "design philosophies" to make nanoscale artifacts. Conventional design is based "on the principles that have served us so well on the macroscopic scale would rely on rigid materials, components that are fabricated to precise tolerances, and the mutually free motion of parts with respect to each other. As we attempt to make smaller and smaller mechanisms, the special physics of the nanoworld - the constant shaking of Brownian motion

\footnotetext{
${ }^{15}$ Jones (2004)

${ }^{16}$ Ibi. p. 86
} 
and the universal stickiness that arises from the strength of surface forces - will present larger an larger obstacles that we will have to design around". ${ }^{17}$ Nanodesign should be based on the principles used by cell biology, labeled 'soft engineering'. It should not "treat the special features of the nanoworld as problems to be overcome, instead it exploits them and indeed relies on them to work at all". ${ }^{18}$

Given such differences, to what extent bio-inspiration may provide engineering principles? So striking is the contrast in Jones's book that his notion of "machine" sounds odd. It conveys near-fantastic and surrealist images à la Dali. In the course of a discussion on this issue, Alfred Nordmann argued that Jones does not really provide an example of bio-inspired machine. He is not really concerned with technology. Nature provides an ideal that will never produce real machines but 'phantom machines' - teleological ideals rather than technological solutions. However, soft engineering provides clues for highly 'concrete technology' in the technical meaning of this term. The term 'concretization' is used by Georges Simondon, a French philosopher of technology. ${ }^{19}$ Concretization consists in turning obstacles into conditions. A concrete machine works precisely because of (and not despite) its association with a specific environment. The environment where the machine will operate is not an external feature or a simple parameter that engineers have to take into account in the design process. The milieu is not something to which the machine will have to be adapted; it is an intrinsic aspect of the design of the machine. This is the major lesson provided by biological processes of self-assembly. ${ }^{20}$

Jean Marie Lehn who developed bio-inspired self-assembly strategies in supramolecular chemistry ${ }^{21}$ moved on to a program of "dynamic combinatorial chemistry", which emphasizes another aspect of biomimetics. Lehn's "Aufbau strategy" relies on the information stored at the molecular level. But information is processed through interactions between molecules. Self-assembly requires an "internal communication" between the components ${ }^{22}$, so to speak a society of molecules. "A glass of water is not like a water molecule", Lehn often says to stress that isolated molecules do not behave like interacting molecules. After inducing molecular recognition between artificial receptors and their substrates, the next step is to build up systems through the controlled self-assembly of supramolecular architectures. And the third step is to induce adaptation and evolution. Lehn's dynamic combinatorial chemistry can be described as a program mimicking Darwinian evolution. The components mixed in a solution explore the possibilities of binding and this dynamics ends up with the correct double helix. Unlike the lock and key static model of recognition, which presupposes that the correct target has been identified, in this process the lock and the key select each other, through a random process of interactions. The basic concepts are "from static to dynamics, from real to virtual,

\footnotetext{
${ }^{17}$ Ibid., p. 127

18 Ibid.

${ }^{19}$ Simondon (1989)

${ }^{20}$ Whether biological systems designed by Darwinian evolution are optimized or not is the matter of ongoing debates. S.J. Gould, R.C. Lewontin, (1979) For Jones biological systems are optimized and provide a norm rather than inspiration for nanotechnology. "The insights of molecular cell biology show us more and more clearly how optimised nature's machines are for operation at the nanoscale. ...] Nature has evolved to get nanotechnology right.(p.7) By contrast, Whitesides points out a major limit of bio-inspiration for self-assembly: biosystems do not make use of magnetic interactions which could prove very promising in technological systems because they are rather insensitive to environment. But here is precisely the key feature of self-assembly in biological systems. It is a process involving environment-sensitive properties, and responding to environmental changes.

21 Lehn (1995)

${ }^{22}$ Lehn (2006)
} 
and from prefabricated to adaptive". ${ }^{23}$ The solution in the vessel potentially contains all possible combinations between the components. Or to go back to the car metaphor, the box contains not just the parts of one car, but the parts of all possible cars (from $2 \mathrm{CV}$ to Formule 1) and the output depends on mutual adaptation. This blind process is not unlike the process of creation of order out of chaos in ancient Greek atomistic cosmogonies. Lehn insists on the analogy with artistic creations in poetry and music such as Pierre Boulez's combinatorial composition. ${ }^{24}$

\section{Integration}

Integrative technology is a program carried by Carlo Montemagno, an engineer and professor of Biomedical Engineering. ${ }^{25}$ It combines both previous strategies since the purpose is to hybridize living and non-living systems, in order to make artificial devices mimicking membranes or muscles. Most research projects are oriented towards biomedical applications. They try to mimic the brain activity with artificial vesicles, with units performing a specific task. However the ambition is to create systems that offer emergent capabilities through extensive use of nature's models of molecular interactions and supra molecular assemblies.. « Integrative technology, the fusion of Nanotechnology Biotechnology and Information technology, provides the ability to build artificial organelles, functional units that manifest emergent properties that result from the stochastic non-linear interactions between the components of the system." 26

Membranes are key actors in this program, because of their multiple functions: they determine the spatial organization, supply electricity, sense and relay information, detect specific molecules. On this basis it is conceivable to engineer an artificial membrane that processes information in a biological sense, and responds to its environment. For instance, the project aimed at producing excitable vesicles is explicitly conceived as an illustration of the emergence of higher-order properties. ${ }^{27}$ By incorporating ion channels into a biomimetic membrane the purpose is to make a responsive system that will generate ionic currents when stimulated. Then by treating each vesicle as a neuronal mode the next purpose is to engineer computational units. Systems of excitable vesicles should be capable of performing various functions of the brain. It would execute rapid and precise pattern recognition from incomplete data sets, and process information from different sources.

The integrative program is grounded on a specific view of living systems. They are complex machines made of simple molecular devices. The machine metaphor differs from the clockwork mechanism (Cartesian model) underlying the hybridization program previously described. The cell is a computer, an information processor, with a physical separation between the machinery (the metabolic processes) and the program (chromosomes). It is more like a Turing machine with algorithmic complexity. This model combining biochemistry with artificial intelligence and neuronal studies is widespread in the nanotechnology community as well as in synthetic biology communities.

It differs from the biomimetic model because of the lack of concern with interactions with the environment. Ironically the so-called "integrative technology" is not deeply concerned with how to integrate artifacts within biological environments. How to avoid adverse effects due to

\footnotetext{
${ }^{23}$ Lehn (1999).

${ }^{24}$ Lehn (2004)

25 Montemagno (2001)

${ }^{26}$ Montemagno (2004) p. 39

${ }^{27}$ Montemagno (2004)
} 
immune responses is not an issue. And the least concern is how to get the artifact to work together with the biological environment in order to make a "concrete machine". Integration is not an issue because the underlying assumption is that molecules, cells and neurons are of the same nature, they are all computer-like.

To sum up this section, the three types of self-assembly programs here outlined are based on quite different views of nature. In the hybridization program $\left(\mathrm{N}^{\circ} 1\right)$, living systems are collections of independent devices that can be put at work in artificial machines like mechanisms assembled in a clock. Hybridization is a strategy inviting a process of fabrication. It requires both a designer - a clockmaker who designs an overall project or a player who has the whole picture of the jigsaw puzzle - and a strict control of the process. In the integrative program $\left(\mathrm{N}^{\circ} 3\right)$ there is also a designer although the project is to build a system that manifests functionality not constitutive of its components, with emerging properties. By contrast, biomimetic self-assembly (program $\mathrm{N}^{\circ} 2$ ) is a blind process of creation through combinations and selection without external designer. Although chemists often use the paradoxical phrase 'we self-assemble molecules', the process is going on without human involvement. The subject "we" just initiates the process of self-assembly by securing the necessary agencies and appropriate conditions. One would hardly dare say that they 'engineer' structures or machines whereas Montemagno can be adequately presented as a "medical engineer".

Such opposite views get with alternative technological styles. For chemists such as Whitesides and Lehn, self-assembly may not be a key for nanotechnology. Whitesides insists that self-assembly is not confined to the molecular level and noted that biological structures are relatively large compared to the devices designed in nanoelectronics or nano-optics. ${ }^{28}$. $\mathrm{He}$ even stated that self-assembly is more suitable and more promising at the mesoscale. ${ }^{29}$ Lehn is even more radical in divorcing self-assembly from nanotechnlogy. For him selfassembly and dynamic combinatorial chemistry offer an alternative to nanotechnology attempts at working with individual and isolated molecules. ${ }^{30}$

\section{Towards a molecular vitalism?}

The current concern with self-assembly is more than a convenient process for engineering at the nanoscale where human intervention is no longer feasible. Beyond the technological or medical purposes driving most research programs, self-assembly revives a traditional metaphysical issue concerning the distinction between living and non-living systems. Vitalism that one could regard as an obsolete topic tends to become a hot issue again. In June 2007 the editorial of a special issue of the journal Nature devoted to synthetic biology was entitled: "Synthetic biology provides a welcome antidote to chronic vitalism". More seriously three biologists Kirschner, Gerhart and Mitchison devoted an important paper to conceptual issues entitled "Molecular vitalism".

\section{A Strategic Distinction}

Without questioning the importance of genetics and genomics Kirschner, Gerhart, Mitchison campaign against the reductionism embedded in molecular biology and raise the question "to what extent the postgenomic view of modern biology would convince a nineteenth-century vitalist that the nature of life is now understood". ${ }^{31}$ They focus on the distinction between

\footnotetext{
${ }^{28}$ Whitesides (2003) p. 1161.

${ }^{29}$ Whitesides, Boncheva (2004)

${ }^{30}$ Lehn (2004) p. 2462.

${ }^{31}$ Kirschner, Gerhart, Mitchison (2000) p. 79
} 
self-assembly and self-organization. Self-assembly is defined in thermodynamic terms as a system reaching a state of equilibrium, a state of minimum free energy. Self-organization requires two additional conditions: i) a capacity for unitary organization (polarization), ii) a capacity for to regenerate a regular structure when the components are altered (regulation). In their view self-assembly is a doctrine, "an extension of the central dogma of molecular biology bringing us from the realm of linear information to the real of protein assemblies". ${ }^{32}$ By contrast self-organization is observable in organisms or embryos rather than in machines, it marks the divide between art and nature.

It is thus clear that the distinction between self-assembly and self-organization becomes strategic when the issue of the nature of life is raised. Kirshner, Gerhart and Mitchison's distinction can be justified at the conceptual level. Self-assembly - a recent term that emerged in organic chemistry and Materials Science in the 1980s - supports a mechanistic view of life as the notion of assembly connotes technology (assembly line). By contrast the term selforganization was introduced in the late eighteenth-century by Immanuel Kant to mark the distinctive features of organisms. The notion of self-organization resurfaced in the 1970s in two different contexts, cybernetics (in particular John Foester's Biological Computer Laboratory created in 1958) and physical chemistry (Ilia Prigogine's work). Its meaning became closer to the current definition of self-assembly. ${ }^{33}$ For Prigogine self-organization is evolution toward steady-states, which means that self-organized systems are open systems. In fact, according to Stengers, Prigogine took his notion of self-organization from embryologists who used this term in response to the failure of attempts at identifying a specific chemical substance that would induce the process of organization in early embryos. His ambition was to reconcile the biological order with the second principle of thermodynamics by introducing the time arrow in physics. ${ }^{34}$ For John Von Foerster, self-organization means order from noise with decrease of relative entropy, and increase of redundancy within the system. Henri Atlan's publication L'organisation biologique et la théorie de l'information in 1972 retained the view of self-organization as order from noise. However he emphasized that it was complexity from noise. In his view based on Shannon's information theory, self-organization is a process requiring a hierarchical multilevel system and initial redundancy, so that it leads to a decrease of redundancy. Like Kirshner, Gerhart and Mitchison, Atlan insisted on the originality of self-organization, by stressing the contrasts between biology and human technologies. Noise, a major obstacle for engineering projects is the condition for generating order in "natural machines". Living organisms turn our major obstacles into operating conditions. "Noise, for the former [communication engineers] is a bitter pill, for the latter [biology] it is the spice of life. Redundancy for communication engineers is a burden. It is a bonus for biologists". ${ }^{36}$ Atlan characterized self-organization by its creative power. On the basis of a study of immune systems, he argues that self-organization is more than a creation of information out of noise it also creates "meaning". The discrimination between self- and notself is not just a deterministic reflex programmed in the genes. It is described as the result of "a dynamic process of continuing challenges and responses". ${ }^{37}$ Thus selforganization becomes a process of individuation, which is radically different from selfassembly. Self-assembly may result in the production of aggregates but it will never generate an individual unit, since for Atlan the individual is not a product of some obscure mechanism,

\footnotetext{
${ }^{32}$ Ibid. p. 80

${ }^{33}$ Stengers (1985)

${ }^{34}$ Stengers (1985) p. 36

${ }^{35}$ Atlan H, (1972) and (1979)

${ }^{36}$ Atlan H, Cohen I.R., 2006, p. 125.

${ }^{37}$ Ibid., p. 137
} 
it is the process itself of interactions with a unique environment.

\section{Alternative metaphysical agendas}

To what extent research programs focused on self-assembly, revive the ambition to provide physical-chemical accounts for the emergence of life or defend the alternative vitalistic position through a clear-cut distinction between self-assembly and self-organization? To answer the question requires a more precise view of the relation between scientific research programs and metaphysical views. In the first section I tried to dig out the tacit metaphysical assumptions underlying research practices. Here I will focus on the metaphysical agendas that a number of scientists explicitly state in their publications. Such metaphysical claims proliferate on the margins of research papers, in commentaries, in semi-popular articles or in blogs, and they often belong to the regime of promises. In fact similar scientific practices and metaphysical views can lead to divergent metaphysical agendas.

For instance, a clear-cut distinction between self-assembly and self-organization is strongly recommended by Richard Jones.

"People use different definitions, but it seems to me that it makes lots of sense to reserve the term self-assembly for equilibrium situations. [...] We can then reserve selforganization as a term for those types of pattern forming system, which are driven by a constant input of energy. A simple prototype from physics are the well-defined convection cells you get if you heat a fluid from below, while in chemistry there are the beautiful patterns you get from systems that combine some rather special non-linear chemical kinetics with slow diffusion - the Belousov-Zhabotinsky reaction being the most famous example. "38

Jones relies on the thermodynamic notion of self-assembly as the minimization of free energy in a closed system, which leads to equilibrium state. For instance, phospholipids with hydrophobic and hydrophilic ends placed in aqueous solution spontaneously form a stable structure. Self-organization only occurs far from equilibrium, in open systems, as it requires external energy source. It is a production of order out of irreversible process with energy dissipation. It is a local phenomenon illustrating the significance of singularities, out of the scope of statistical mechanics.

By contrast, George Whitesides does not care for any distinction between self-assembly and self-organization. He rather defines two types of self-assembly: the static one - resulting in equilibrium state- and the dynamical one, with energy dissipation. ${ }^{39}$ Dissipative structures are thus given as examples of self-assembly. This is all the most striking that Whitesides deplores the current abuse of the term self-assembly and tries to provide a more focused definition: "'Self-assembly' is not a formalized subject, and definitions of the term "self-assembly" seem to be limitlessly elastic. As a result, the term has been overused to the point of cliche'. Processes ranging from the non-covalent association of organic molecules in solution to the growth of semiconductor quantum dots on solid substrates have been called self-assembly. Here, we limit the term to processes that involve pre-existing components (separate or distinct parts of a disordered structure) are reversible, and can be controlled by proper design of the components. "Self-assembly" is thus not synonymous with 'formation., ${ }^{40}$ Despite his efforts to limit the notion Whitesides's definition embraces a wide variety of processes ranging from crystallization on surfaces, templated synthesis to cell's functions and schools of fish. Thus Whitesides extends the realm of self-assembly to all length-scales from atoms to galaxies via

\footnotetext{
${ }^{38}$ Softmachine blog, Nov 152005 http://www.softmachines.org/wordpress/?m=200511

${ }^{39}$ Whitesides, Grzybovski (2002)

${ }^{40}$ Whitesides, Grzybovski (2002) p.2418.
} 
biology. ${ }^{41}$ Far from confining self-assembly to the nanoscale, Whitesides and his collaborators argue that self-assembly works at all scales and that its future lies primarily at the mesocale. ${ }^{42}$

Lehn uses both terms more or less interchangeably to characterize the synthesis of supramolecular architectures. He just assumes that self-organization is self-assembly with the production of a precise structure - such as double-helix metal complexes and pentagonal or hexagonal grids, depending on the nature of the metallic ion used. He insists on interactions between molecules and their collective behavior. Considering that isolated molecules do not behave like interacting molecules, that a glass of water is different from of water molecule, Lehn assumes that something emerges from their "being together". Togetherness was precisely one major feature of Prigogine's notion of self-organization according to Isabelle Stengers. It implies not only "being together" but "acting together", a collective behavior which results from coupling processes rather than just expressing information contained in the components. Thus for Lehn, controlling the basic forces of self-organization is the ultimate aim of chemistry.

Indeed one may ask: Does it really matter whether dissipative structures are viewed as a variety of self-assembly or as a variety of self-organization? Who cares for the multiple meanings and different extensions of the notions of self-organization and self-assembly? In most natural sciences, definitions are a matter of convention, and sometimes a matter of convenience. Loose boundaries occasionally proved fruitful to the advancement of science. Moreover they testify to the fact that this concept is very successful. From the point of view of the dynamic of knowledge, Sabine Maasen argues that "the price of a term being successful is its increasing vagueness - and the perceived need for each individual field of research to define (and hence limit) its use." 43

\section{Science War?}

Such distinctions are strategic for delineating territories between rival paradigms. It has to do with the demarcation between the respective territories of chemistry and biology. Jones's criteria of demarcation based on equilibrium and far from equilibrium draws a clear-cut boundary assigning self-assembly to physicists and chemists while self-organization remains the major feature of life. "Self-assembly is not in itself biology, it is used by biology. A system organized by equilibrium self-assembly is moving toward equilibrium and things at equilibrium are dead." ${ }^{44}$ Jones claims that although information stored in the sequence of amino-acids accounts for protein folding, life is more than just information; it is also metabolisms. Nevertheless the physicist's approach is relevant to increase our understanding of biological systems in so far as life is not an isolated system and complies with thermodynamics second law.

By contrast, Whitesides's strategy of expanding the domain of self-assembly is in keeping with his belief that chemistry is everywhere and must go everywhere. ${ }^{45}$ Chemistry so far confined to the interactions between atoms and molecules using strong covalent bonds is expanding its territory, by using the whole spectrum of weak forces and operating at various scales. Chemical language can decipher the most complex phenomena: "The nature of the cells is an entirely molecular problem. It has nothing to do with biology". ${ }^{46}$ And since

\footnotetext{
${ }^{41}$ see Table 1 in Whitesides, Grzybovski (2002)

${ }^{42}$ Whitesides, Boncheva, 2002.

${ }^{43}$ Maasen, 2006

${ }^{44}$ Jones, softmachines blog, March,14, 06 How much should we worry about bioNT?

${ }^{45}$ Whitesides, 2004.

${ }^{46}$ Whitesides quoted by Philip Ball (2006) p. 501.
} 
neurons also use chemical mediators, chemists should also contribute to merge silicon electronics with the brain.

Similarly Lehn's program of Constitutional Dynamical Chemistry revives the greatest ambitions for chemistry. His program evolving from supramolecular chemistry to dynamic combinatorial chemistry looks like a modern replica of Berthelot's grandiose program of synthetic chemistry, which would gradually lead him, step by step, to more and more complex compounds and ultimately to the frontiers of life. ${ }^{47}$ Lehn portrays chemistry as the "science of informed matter", a core science mediating inanimate matter (materials process) and animate matter (living organisms and their complex behaviors). ${ }^{48}$

Self-assembly has revived the chemists' ambition to access the "essence of life". As Philip Ball rightly points out, chemists are now addressing the "big questions" about the Big Bang and the origin of life. Far from confining their work to the production of utilities, chemists want to address questions about the origin of life and of consciousness: "For me, Lehn says, chemistry has a most important contribution to make to the biggest question of all: how does self-organization arise and how does it lead to the Universe to generate an entity that is able to reflect on its own origin?"49

To an outside observer, this expansionist attitude strikes as being at odds with the current consensus about the merits of cross-boundary research and interdisciplinary programs. How is it possible to hear such passionate advocates of a discipline when the leaders of the program Converging Technologies announce that the age of scientific specialties is over:

"The sciences have reached a watershed at which they must unify if they are to continue to advance rapidly. Convergence of the sciences can initiate a new renaissance, embodying a holistic view of technology based on transformative tools, the mathematics of complex systems, and unified cause-and-effect understanding of the physical world from the nanoscale to the planetary scale." 50

Although interdisciplinary teams and cross-boundary research programs are flourishing and have demonstrated their efficiency on some occasions, it seems that the grand unifying understanding of the world is neither for today, nor for tomorrow... unless unifying means reducing everything to atoms and molecules.

\section{A common plea against reductionnism}

The current focus on self-assembly did re-open the debate over vitalism but it would be oversimplistic to conclude that the fireline between the advocates of vitalism and advocates of mechanism follows disciplinary boundaries. The map of the battlefield is more complex. The fireline has significantly shifted. It is no longer a matter of disciplinary affiliation because the distinction between living and non-living does not really make sense at the nanoscale. In fact, in various scientific communities - physics, chemistry, biology, artificial life, etc - a number of individual scientists are using self-assembly or self-organization as watchwords against reductionism.

Both Whitesides and Lehn claim that their views of chemistry are not reductionist. Lehn insists that it is chemistry, which is becoming complex, adaptive and evolutive. Whitesides claims that chemistry so far was «blindly reductionist » and that chemists will have to move

\footnotetext{
${ }^{47}$ See Bensaude-Vincent \& Stengers (1996) p. 152-154

${ }^{48}$ See Lehn (2002) Table 3 on p. 2402.

${ }^{49}$ Lehn quoted by Ball (2006) p. 501.

${ }^{50}$ Roco, Bainbridge (2002) p. xii
} 
« beyond molecules to learn the entire problem ». ${ }^{51}$ Just as Prigogine's ambition was not to reduce biological systems to physics or chemistry, both of them assume that chemistry has the power to explain living systems because chemistry in turn is deeply transformed by its application to complex phenomena. Just as Prigogine imported in physics the problem of collective behavior or « how to act together » that had been raised by embryologists in their use of the term self-organization, ${ }^{52}$ Lehn is importing the same problem at the molecular level. In plagiarizing Feynman's too famous phrase one could say: there is plenty of room for complexity at the bottom, if you look carefully at the collective behavior of molecules! To a certain extent biologists such as Kirshner, Gerhart and Mitchison agree with the chemist Jean-Maris Lehn on this point. They assume a continuity between self-assembly and selforganization for a single cell. At the level of one single cell, self-organization is just an extension of self-assembly employing chemical strategies in order to break symmetry. The formation of ordered aggregates by the self-assembly of identical components generates an asymmetry and leads to polarization. So polarization and regulation - the two distinctive features of self-organization in single cells - may be viewed as simple extensions of selfassembly. By contrast, when self-organization occurs at the system level (for instance in embryos) it is a quite different phenomenon. It involves exploration of an assembly landscape and selection of a functional steady-state. It implies a diversity of states offering possibilities for selection.

Thus the dividing line no longer delineates chemistry from biology. Rather the contrast is between two alternative approaches to molecular phenomena: either considering single molecules or their collective behaviors. Kirshner, Gerhart, Mitchison claim that it is time to move beyond the genomic analysis of proteins and RNA components of the cell in order to understand the robustness of biosystems. Lehn claims that it is time to move to a dynamic combinatorial chemistry.

In conclusion, the current interest in self-assembly is not just born out of the bare necessity to explore a technique for making artifacts at the nanoscale level. It is also driven by big metaphysical issues concerning the nature of life. The ambition to account for the circumstances and mechanisms at work in the emergence of life underlies a number of research programs for directing the self-assembly of molecules. In this respect, the conceptual distinction between self-assembly and self-organization offers a strategic field for reigniting the debate betwen vitalism (stressing the difference between the organization of living systems and machines) and mechanism (stressing their analogy with the connotation of assembly line).

However the contrast between assembly and organization no longer refers to the divide between chemistry and biology. It is not the continuation of the long tradition of the chemists conquistadores who pretended to be able to make life in a test-tube. Rather it is an urge to go beyond the current reductionism that characterizes the molecular approach to chemical and biological phenomena.

The emphasis today is more on the prefix "self", than on the alternative assembly or organization. The prefix "self" may refer to diverging strategies of self-assembly as well as diverging metaphysical agendas. ${ }^{53}$ In hybridization programs as well as in the so-called integrative approach, the "self" refers to a functional device, which is isolated as a separate part of a machine. The result is a logical machine embodied in a physical structure. By contrast in biomimetic strategies, "self" refers to a population of interconnected molecules exploring the various possibilities of collective behavior.

\footnotetext{
${ }^{51}$ Whitesides (2004)

${ }^{52}$ Stengers (1985) p. 82

53 See Dupuy (2000)
} 


\section{REFERENCES}

Atlan, H. (1972) L'organisation biologique et la théorie de l'information. Paris, Hermann.

Atlan, H. (1979) Entre le cristal et la fumée, Paris, Seuil-Point science.

Atlan, H. \& Cohen Irun R. (2006) "Self-organization and meaning in immunology" in B.

Feltz \& M. Crommelinck, P. Goujon eds, Self-Organization and Emergence in Life Sciences, Springer, The Netherlands, p. 121-139.

Ball, Philip (2002) "Natural Strategies for the molecular engineer", Nanotechnology, 13, p. 15-28.

Ball, Philip (2006) "What chemists want to know", Nature, 442, Aug 2006, 500-502.

Bensaude-Vincent, B., Stengers I (1996) A History of Chemistry, Cambridge Mass, Harvard

University Press.

Bensaude-Vincent, B., Arribart, H., Bouligand, Y., Sanchez, C., 2002: "Chemists at the School of Nature", New Journal of Chemistry, 26, 1-5.

Bensaude-Vincent B. \& Guchet X. 2007, «Nanomachine : One word for three different paradigms », Technê, Research in Philosophy \& Technology, 10, $\mathrm{n}^{\circ}$ 3, Spring 2007.

Bernard C., [1878] Sixième Leçon in Leçons sur les phénomènes de la vie communs aux animaux et aux végétaux, Paris, Vrin, 1966.

Berthelot M., 1897 : La synthèse chimique, Paris, Alcan, 8th edition.

Boxer S. quoted in "Exploiting the Nanotechnology of Life", Science, 254, 29 November 1991, 1308-09.

Brooke, J.H., 1973, "Organic Synthesis and the Unification of Chemistry - A Reappraisal", British Journal for the History of Science, 4, 362-392.

Breen T.L., Tien J, Oliver S.R, Hadzic T, Whitesides G.M. (1999) "Design and self-Assembly of open, regular, 3D mesostructures", Science, 284, May 7, 948-951.

Canguilhem G., [1947]. "Machine et organisme", in La connaissance de la vie, Vrin, Paris, 1971, p. 101-127.

Drexler, Eric K, 1986, Engines of Creation, New York, Anchor Books, second edition, 1990.

Dupuy, J.P., 2000: The Mechanization of the Mind, Princeton N.J., Princeton University

Press.

Gould Stephen, R.C. Lewontin, 1979, "The spandrels of San Marco and the Panglossian

Paradigm : A critique of the adptationist programme", Proceedings of the Royal Society of

London, Series B, vol. 205, issue 1161,( sept 21 1979), 581-598.

Jones, R.L., 2004: Soft Machines, Oxford University Press, Oxford, New-York.

Jones, R.L. Softmachines blog, http://www.softmachines.org/wordpress/?m=200511

(accessed January 2009)

Keren K, Berman R S., Buchstab E., Sivan U., and Braun E. (2003) " DNA-templated carbon nanotube field-effect transistor, " Science, 302, Nov 21 2003, 1380-1382.

Kirschner M, Gerhart M., Mitchison T. (2000) "Molecular Vitalism”, Cell, 100, jan. 7, 79-88. Lehn J.M. (1995), Supramolecular Chemistry, VCH, Weinheim,

Lehn J.M. (1999) ,"Dynamic combinatorial chemistry and virtual combinatorial libraries“,

Chemical European Journal, 5, N9, p. 2455-2463.

Lehn J.M. (2002) "Toward self-organization and complex matter", Science, 295, 29 March 2002, p. 2400-2403.

Lehn J.M. (2004) "Entretien avec Jean-marie Lehn sur les possibles naturels en chimie", Revue de métaphysique et de morale, $\mathrm{N}^{\circ} 3$, p. 371-380.

Lehn (2006) "From supramolecular chemistry to molecular dynamics", Plenary Lecture at the First European Chemistry Congress, Budapest, 27-31 August, 2006.

Livet Pierre, 1985, "Cybernétique, auto-organisation et néo-connectionisme", Cahiers $d u$ CREA, $\mathrm{N}^{\circ} 8,105-153$ 
Maasen S (2006) "The assembled self of nanotechnology: The career of self-assembly as a metaphor", paper presented at EASST Conference, Lausanne, Aug 2006.

Montemagno CD (2001) "Nanomachines: A Roadmap for Realizing the Vision," Journal of Nanoparticle Research 3, 1-3.

Montemagno CD (2004) "Integrative technology for the 21st century" In Roco M. \& Montemagno C.D. eds The co-evolution of Human Potential and Converging technologies, Annals of the New York Academy of Science, 1013, 38-49.

Newman William R., 2004 Promethean Ambitions: Alchemy and the Quest to Perfect Nature, Chicago, university of Chicago Press.

Ramberg P (2000) "The Death of Vitalism and the Birth of Organic Chemistry : Wölher's Urea Synthesis and the Disciplinary Identity of Chemistry", Ambix, 47, 170-195.

Roco, Michael, Bainbridge W. (2002) Converging Technologies for Improving Human

Performance Nanotechnology, Biotechnology, Information technology and Cognitive Science National Science Foundation Report, Arlington.

Sarikaya et Aksay eds (1995) Biomimetics : Design and processing of Materials, AIP

Press, Woodbury.

Simondon, G. (1989) Du mode d'existence des objets techniques, Aubier, Paris.

Stengers Isabelle (1985) «Les généalogies de l'auto organisation", Cahiers du CREA, $\mathrm{N}^{\circ} 8$, 7-104.

Stengers Isabelle (1997) Cosmopolitiques, Paris, éditions la découverte, 7 volumes ; vol. 6 La vie et l'artifice: Visages de l'émergence.

Whitesides, G.M. (1995) "Self-Assembling Materials", Scientific American, sept : 146-149

Whitesides G. M. (2002) “Organic Materials Science”, MRS Bulletin, January 2002, 56-65. Whitesides G.M. (2003) "The 'right' size in nanobiotechnology", Nature Biotechnology, 21, October 10, 1161-65.

Whitesides, G.M. (2004) "Taking chemistry in new directions", Angewandte Chemie Int. Ed. 43, $3632-3641$.

Whitesides G. M.,Boncheva M.(2002) "Beyond molecules: Self-assembly of mesoscopic and macroscopic components", Proceedings of the National Academy of Science, 99, April 16, 2002, 4769-4774.

Whitesides G.M., Grzybowski B. (2002) « Self-assembly at all scales », Science, 295, March 19, 2002, 2418-21.

Whitesides, G.M., Wong A.P. (2006) "The intersection of Biology and Materials Science", MRS Bulletin, 31, January 2006, 19-27

Zhang Shuguang (2003) "Fabrication of novel biomaterials through molecular self-assembly", Nature Biotechnology, 21, N¹0, Oct 2003,1171-78. 